\title{
A REMOTE SENSING CLASSIFICATION FOR LAND-COVER CHANGES AND MICRO-CLIMATE IN KUWAIT
}

\author{
S. UDDIN, A.N. AL GHADBAN, A. AL DOUSARI, M. AL MURAD \& D. AL SHAMROUKH \\ Environment Sciences Department, Environment and Urban Development Division, Kuwait Institute \\ for Scientific Research, P.O. Box 24885, Safat 13109, Kuwait.
}

\begin{abstract}
The paper addresses the issue of micro-climatic variations due to changing land-cover in the study area. Kuwait has undergone a unique environmental catastrophe during 1991 Gulf war in the form of oil lakes and spills on land, which has left permanent scars on the desert surface. The region is experiencing large scale urban expansion with the growing population needs and political stability. New townships planned with expansion of existing ones, rapid development in petroleum sector, all these developments are resulting in Urban Heat Island (UHI) effect both over the city and the hydrocarbon contaminated sites. In this study the Landsat image of 1989, 1991 and 2000 are used to compute surface temperature and land-cover classification to understand the relationship between micro-climate and land-cover. The results have shown increased temperatures over both the built-up areas and hydrocarbon contaminated surface. The long term temperature trend in the area shows an incremental trend since 1980s, which increases sharply in post 1990s, probably due to cumulative effect of hydrocarbon pollution, urban-industrial development and increased carbon emission. The study utilized the novel approach of land-cover classification using the Normalized Difference Vegetation Index (NDVI), Normalized Difference Water Index (NDWI), Normalized Difference Built-up Index (NDBI) and Normalized Difference Bareness Index (NDBare). These indices are related to the Land Surface Temperature (LST) computed using satellite datasets. Results show a negative correlation of NDVI, NDWI, and NDBare with surface temperature. NDBI is positively correlated with temperature. Although there are isolated instances where bare surfaces show increased temperature at places and these temperatures are comparable to built-up area, the most pertinent reason for this temperature hike is obliteration of emissive property of desert soil due to hydrocarbon leftovers and mixing of hydrocarbon leftovers with soil for bioremediation. These remediated soils are used in plantation and re-vegetation giving higher thermal signatures, mainly because of scanty vegetation cover.
\end{abstract}

Keywords: hydrocarbon pollution, NDBare, NDBI, NDVI, NDWI.

\section{INTRODUCTION}

The micro-climate of a region is a complex process of energy interactions between earth and the atmosphere. The interactions of earth and the atmosphere are governed by surface heat fluxes, the distribution of which is drastically modified with land-cover changes. The main contributing factors are physical changes of the surface as a result of the replacement of vegetation cover with urban land-use (asphalt and concrete) and decrease of surface moisture available for evapotranspiration.

Since the early 1980s, remote sensing datasets have been used to estimate physical properties of the earth's surface [1-12]. The phenomenon of Urban Heat Island (UHI) has received a lot of attention over the last five decades; following the initial report by Nieuwolt [13] in Southern Singapore. The UHI phenomenon, which occurs when the surface and atmospheric modifications are caused by changing land-use and urban development, results in warming of these land-covers compared to nonurbanized areas. The UHI phenomenon is particularly prevalent at night. The surface temperature is of prime importance to the study of UHI, it modulates the air temperature at lower levels.

The UHI intensity is inversely correlated with the rural temperature, whereas the spatial extent is found to be independent of both the heat island magnitude and rural temperature [14]. Studies on the UHI phenomenon using satellite derived Land Surface Temperature (LST) measurements have been conducted using AVHRR data [14-17] for urban temperature mapping on regional scale. Landsat TM and Landsat ETM+ data with 120 and $60 \mathrm{~m}$ resolutions are useful for LST measurement [18] 
and for studying UHI on local scale $[19,20]$. Studies have shown a close relationship between soil moisture, vegetation cover, and radiant temperature [7]. Since then many studies have been done to establish relationship between LST and vegetation cover. There are various vegetation indices that can be derived using remote sensing images and regression analyses to estimate percent vegetation cover. The Normalized Difference Vegetation Index (NDVI) has been used in semi-arid regions for vegetation productivity and soil moisture $[21,22]$. However to evaluate the state of vegetation it is recommended to use NDVI and Normalized Difference Water Index (NDWI) [23].

The methodology proposed by Chen et al. [23] for establishing the relationship between NDVI, NDWI, Normalized Difference Built-up Index (NDBI) and temperature for UHI identification is adopted in this study. The specific objective of this research is to estimate brightness temperature using Landsat images for the period 1989-2000, to examine the spatial pattern of land-cover change and to establish a quantitative relationship between brightness temperature and land-cover changes in Kuwait.

\section{STUDY AREA}

The study area covers the southern portion of Kuwait. Kuwait is an arid country bounded by Iraq in North and West and Saudi Arabia in South and West (Fig. 1). The eastern border of the country is defined by Arabian Gulf. Southern Kuwait is selected in this study since the scars of 1991 Gulf War in

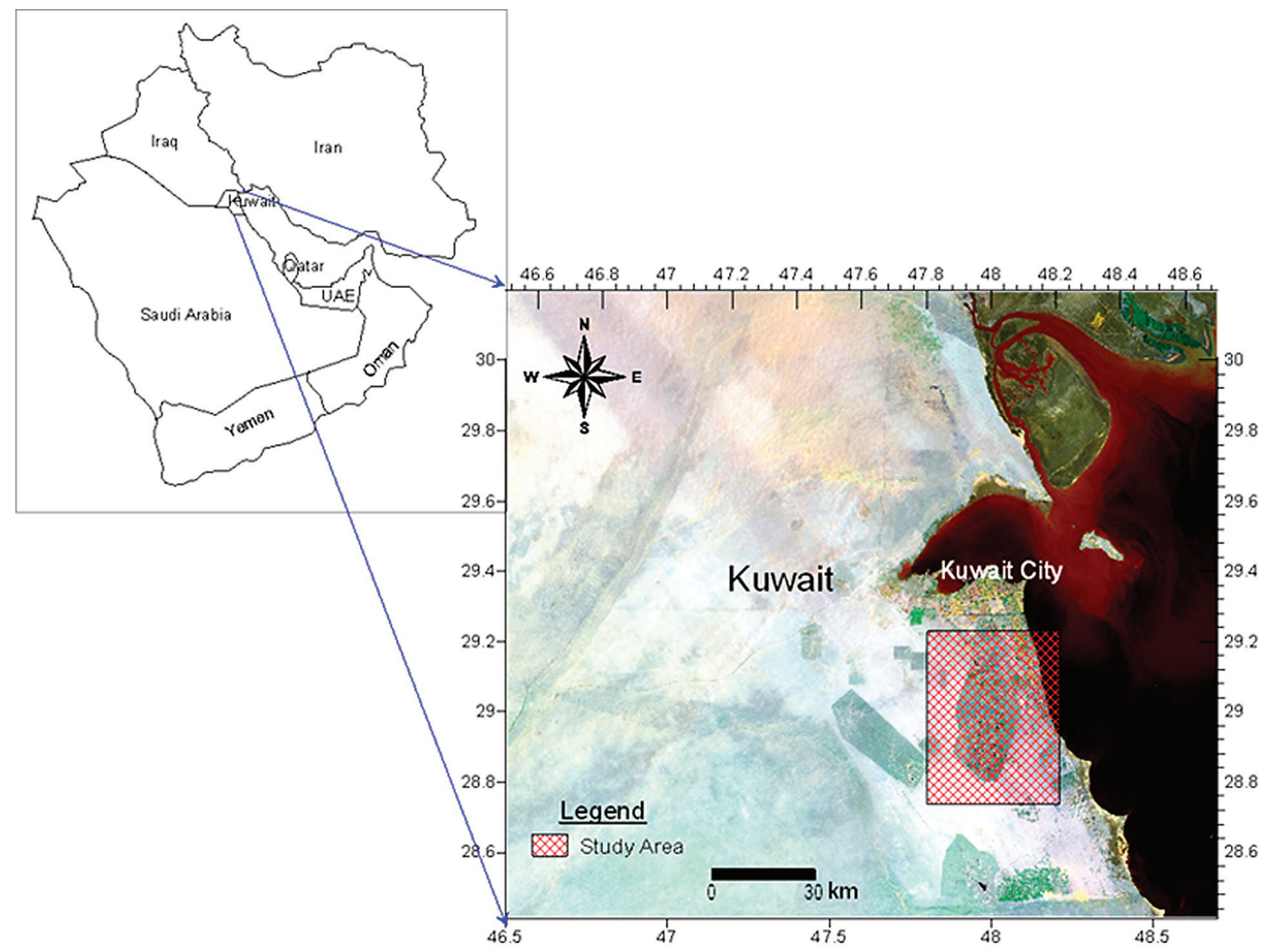

Figure 1: Location map of the study area. 
form of oil lakes and oil polluted surfaces are pronounced in this area. Besides the area has underwent a large scale land-cover change, post 1991 war, in terms of vegetation cover and extensive built-up of oil facility and expansion of townships.

\section{DATA USED}

Landsat TM datasets were used in this study to retrieve LST. The multi-temporal Landsat TM scene of 9th June 1989, 30th May 1991 and Landsat ETM+ scene of 30th May 2000 are used for LST estimation. The resolution of all the images for bands $1-5$ and 7 is $30 \mathrm{~m}$ and the thermal infrared band (band 6) has a spatial resolution of $120 \mathrm{~m}$ for Landsat TM image and $60 \mathrm{~m}$ for Landsat ETM+ image. All the images are geo-rectified to UTM 38R WGS 84 coordinate system.

\section{METHODOLOGY}

The Landsat TM datasets are subjected to adaptive filtering and fast Fourier transformation for noise removal using Geomatica 10 software. The noise removal is critical for LST since it affects the brightness temperature. Multi-temporal Landsat TM and ETM+ images were geo-rectified using an orthorectified IRS P5 Cartosat image. The Landsat images were re-sampled on $30 \mathrm{~m}$ resolution including the thermal bands. The root mean square error for the image is 0.29 .

\subsection{Temperature retrieval}

The temperature estimate from Landsat TM was made in two steps following methodology proposed by Chen et al. [19]. Step 1 involves conversion of band $6 \mathrm{DN}$ value to radiation luminance $\left(R_{\mathrm{TM}}\right)$ using the relation:

$$
R_{T M 6}=\frac{V}{255}\left(R_{\max }-R_{\min }\right)+R_{\min }
$$

where $V$ is the DN of pixel in band 6; $R_{\max }=1.896\left(\mathrm{~mW} \mathrm{~cm}^{-2} \mathrm{sr}^{-1}\right) ; R_{\min }=0.1534\left(\mathrm{~mW} \mathrm{~cm}^{-2} \mathrm{sr}^{-1}\right)$.

Step 2 involves conversion of radiation luminance to at satellite brightness temperature $(\mathrm{T})$ in Kelvin using the relation:

$$
T=\frac{K 1}{\ln \left(K 2 /\left(R_{T M 6} / b\right)+1\right)}
$$

where $K 1$ and $K 2$ are pre-launch constants; $K 1=1260.56 \mathrm{~K} ; K 2=60.766 \mathrm{~mW} \mathrm{~cm}^{-2} \mathrm{sr}^{-1} \mu \mathrm{m}^{-1} ; b=$ $1.239 \mu \mathrm{m}$ (effective spectral range when the sensor response is $>50 \%$ ).

4.2 Derivation of vegetation, water, built-up and bareness indices using Landsat data

The NDVI is the measure of greenness of vegetation cover [24-26]. For Landsat this is expressed as:

$$
\mathrm{NDVI}=\frac{\text { Band } 4-\text { Band } 3}{\text { Band } 4+\text { Band } 3}
$$

NDVI varies between -1 and 1 . Highly vegetated areas show NDVI values between 0.5 and 1 , clouds and water have larger reflectance in visible bands rather than near infra red bands resulting in negative NDVI values. Bare soil, built up area and desert surface have similar reflectance in NIR and red bands, hence they show NDVI values near to zero. 
The concept of NDWI was introduced by Gao [25] to access the water availability in vegetation. The rationale adopted is NIR radiation is absorbed by water thus its availability in plant leaves will be reflected by NDWI. The index is also referred to as Leaf area water absent Index ([23, 27, 28] and water state of vegetation [29]). The value of NDWI varies between -1 and 1 . Negative or near zero values represent built up areas or dry bare surfaces, whereas positive values are obtained for vegetation cover and oil lakes that might have some water content in them.

$$
\text { NDWI }=\frac{\text { Band } 4-\text { Band5 }}{\text { Band } 4+\text { Band5 }}
$$

The radiance of the satellite in the spectral bands is considered.

The concept of NDBI in automatically mapping the urban areas from TM imagery was proposed by Zha et al. [30]. The drastic increment in reflection of built-up area and barren land from band 4 to band 5 has been utilized for making the standard differentiation of these two bands.

$$
\mathrm{NDBI}=\frac{\text { Band5 }- \text { Band } 4}{\text { Band } 5+\text { Band } 4}
$$

The resultant values from this processing show values near to zero for vegetated surfaces, negative values for water bodies and highest values for built-up areas and desert surfaces.

Bareness index was introduced by Zhao and Chen [31] for quick mapping of bare areas from Landsat TM and ETM data. The relation is stated as:

$$
\text { NDBare }=\frac{\text { Band5 }- \text { Band6 }}{\text { Band5 }+ \text { Band6 }}
$$

This relation NDBare is always positive for the bare surfaces, which in the present case include desert surfaces.

These four indices are used to classify different land use and land-covers by adopting these threshold values (Table 1).

\subsection{Relating land use-land-cover to the land surface temperature pattern}

The four indices of vegetation, water, built-up and bareness are used for classifying the images, but determining the threshold value is difficult. In order to resolve this we analyzed the spectral signature of each land-cover type from Landsat TM scene of 30th May 2000. Repetitive sampling for each class is done and the averaged value is adopted as a representative in a particular band (Fig. 2).

Table 1: Threshold values adopted for land-cover classification.

\begin{tabular}{lcclc}
\hline & NDVI & NDWI & NDBI & NDBare \\
\hline Built-up & $<0.2$ & $<0$ & $>0.3$ & $<0.05$ \\
Stabilized desert & $<0.2$ & $<0$ & $0.2-0.3$ & $>0$ \\
Vegetation & $>0.2$ & $>0$ & $<0$ & $<0$ \\
Hydrocarbon contaminated soil & $<0$ & $<0$ & $<0.2$ & $<0$ \\
Oil lakes & $<0$ & $>0$ & $<0$ & $<0$ \\
Desert surface with sand & $<0.2$ & $<0$ & $>0.2$ & $>0$ \\
\hline
\end{tabular}




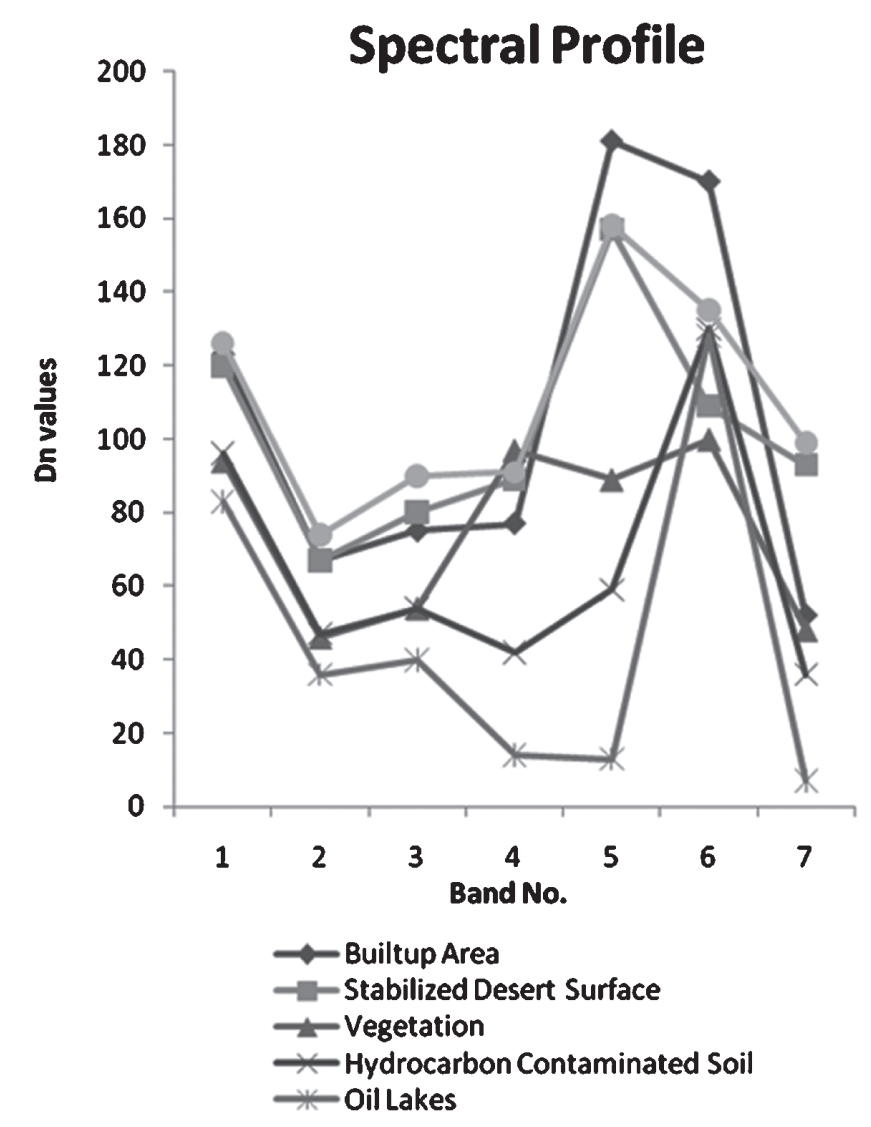

Figure 2: Spectral profile of different land-covers in study area.

To further refine the observation of the various used indices, different indices are combined using Boolean operators (Band $4-$ Band $5>0$ ) is combined with (Band $4-$ Band $3>0$ ) to extract vegetation. Similarly oil lakes were extracted by combining (Band $4-$ Band $5>0$ ) and (Band $3-$ band $4>0$ ). Built-up area were extracted by combining (Band $4-$ Band $3<0$ ) and (Band $4-$ Band $5<0$ ).

Since the signatures of stabilized desert surface and built-up area are quite close to discriminate, the bareness index which significantly differentiates the two land-covers was computed instead. The mean temperature of every land-use/land-cover type is estimated using mono window algorithm [18, 32].

\section{RESULTS AND DISCUSSION}

The approach used for image classification using Boolean operators based on Band DN and vegetation/built-up/water/bareness indices classified the land-cover classes better than conventional supervised and unsupervised classification schemes. The sampling points are randomly selected from various land-cover classes. The overall accuracy of classification is $91.67 \%$ for the six selected land-cover classes. The oil lakes are perfectly classified followed by vegetation, hydrocarbon polluted surfaces, desert surface with sand, stabilized desert surfaces, and built-up area.

Long-term analyses of the temperature data showed significant monthly, seasonal, and interannual temperature fluctuations during the last four decades. The average annual temperature 
seems to have an incremental trend over the region (Fig. 3). In order to study the anthropogenic contribution to global warming, the land-cover-temperature relation is considered.

\subsection{Temperature variations over different land-cover classes}

The LST for each land-cover class was computed using the mono window algorithm [18, 32]. Figure 4 shows a substantial change in surface temperature pattern over the years within similar land-cover classes, which cannot be attributed to vegetation or built-up area. The NDVI was plotted against temperature for each identified class, further confirming that temperature is higher even with higher NDVI values. It is not possible to compare the temperature values across images for different land-cover classes, thus we have considered the intra image UHI intensity variation between landcover classes and the spatial pattern to have a meaningful interpretation of land-cover-temperature relationship. The UHI intensity is measured as a difference between the peak temperature in the urban area and the background rural temperature within the same image.

Interpretation of satellite images shows a very conspicuous change in temperature pattern in preand post-1991 Gulf war images over the study area. Temperature retrievals from 1989 image show a higher temperature over the urban area and sandy desert surface, whereas the higher surface temperature retrievals in 1991 image correlates very well with the hydrocarbon polluted surfaces. The higher the hydrocarbon concentrations, the higher is the retrieved temperature [18].

Contradictory to the popular belief that vegetated surfaces are cooler than others, we have observed higher vegetation index for year 2000 image but none the less with increased spatial extent of higher temperature zones (Fig. 5). The temperature anomalies in post-1991 images (Fig. 4) are well correlated with the hydrocarbon polluted soils, oil lakes [18] and development of the oil facilities in the study area. The intensity of the UHI shifts with season and land-cover. In order to minimize the impact of seasonal difference, two images corresponding to 30th May 1991 and 30th May 2000 are selected to study the land-use/land-cover-UHI relationship during 1991-2000 in Kuwait. Further to

\section{Average Annual Temperature}

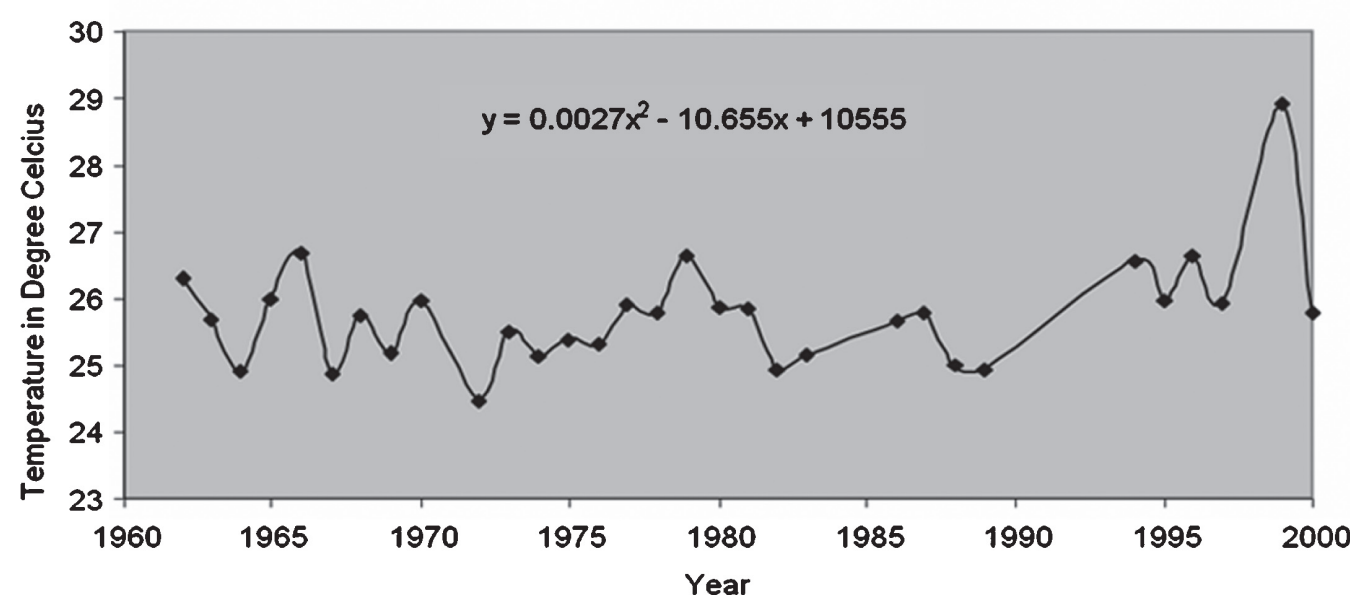

Figure 3: Average annual temperature from 1960 to 2000. 

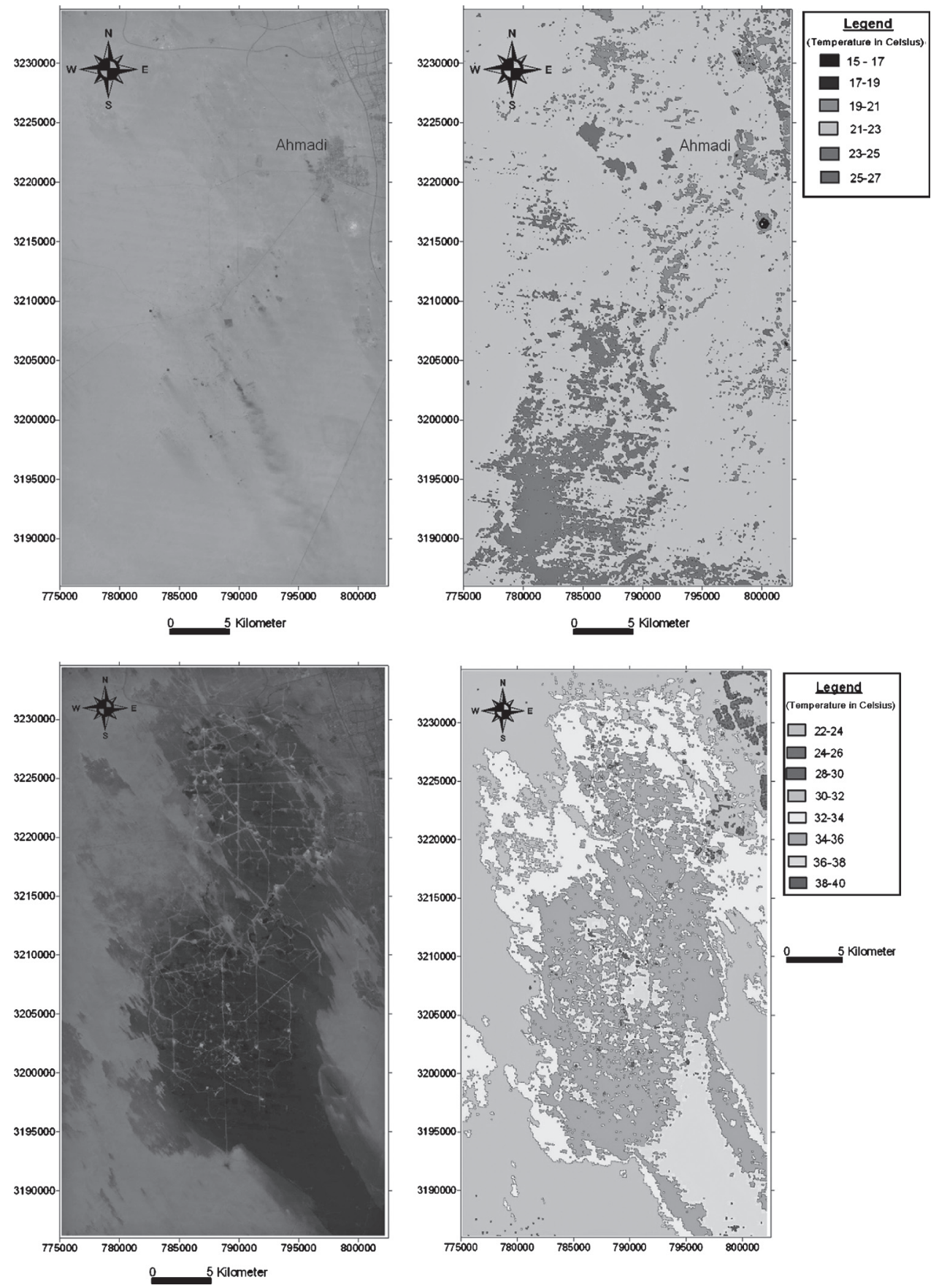

Figure 4: LST of images pertaining to 1989, 1991 and 2000. 

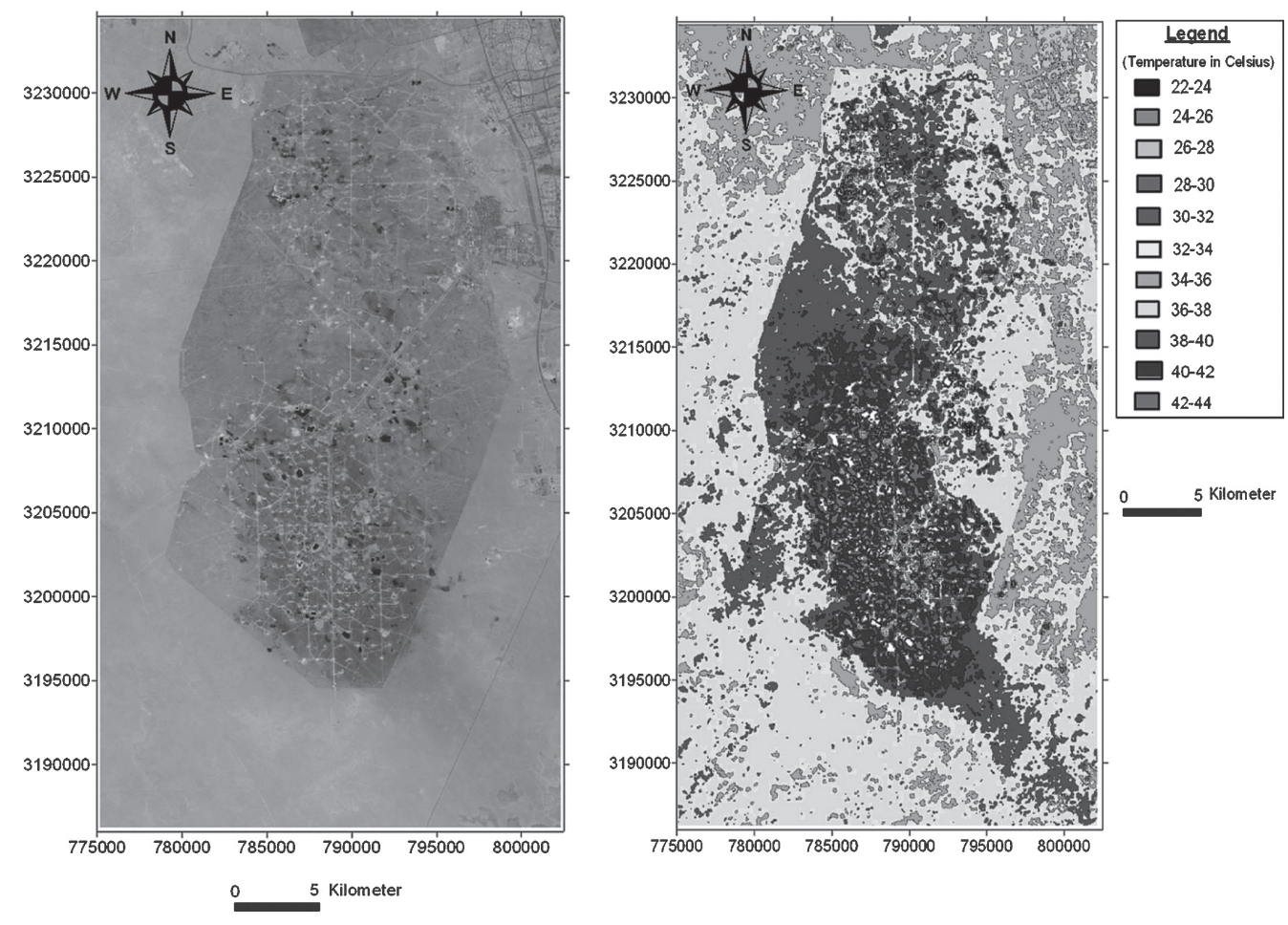

Figure 4: Continued

minimize the difference in temperature and atmospheric condition on the two acquisition dates the UHI intensity is considered rather than absolute temperature. The minimum and maximum temperature in the study area corresponds to vegetation and oil lakes, this is adopted as UHI intensity. Analyses of these images show that the UHI is not only an expression of urban development but can be also due to various other factors, in this study, like hydrocarbon polluted soils, oil lakes and increased emission of green house gasses.

\section{CONCLUSIONS}

The study shows a better classification scheme for land-use/land-cover classification in relation to temperature by considering NDVI, NDWI, NDBI and NDBare. The NDVI, NRWI and NDBare are negatively correlated with temperature on a local scale whereas NDBI is positively correlated with temperature. The $0.08^{\circ} \mathrm{C}$ increase in annual temperature estimated by $\mathrm{Al}$ Fahed et al. [33] is possibly an underestimate. The UHI coverage in Kuwait is wide as it includes a wide area outside the actual urban center including the oil operations in desert and hydrocarbon polluted surface in study area which has obliterated the emissive property of the desert surface, a complex jargon of oil operation in larger part of the desert, extremely high evaporation and evapotranspiration rate due to high temperatures and increased emission of green house gasses. The atmospheric temperature strongly influences the LST, and vice versa. Since the water vapor content and soil moisture content is very low the surface and atmospheric temperatures are reasonably close. We suspect a strong influence of green house gasses in obliterating the micro-climate which has not been explored in great details but is surely a major contributing factor. 


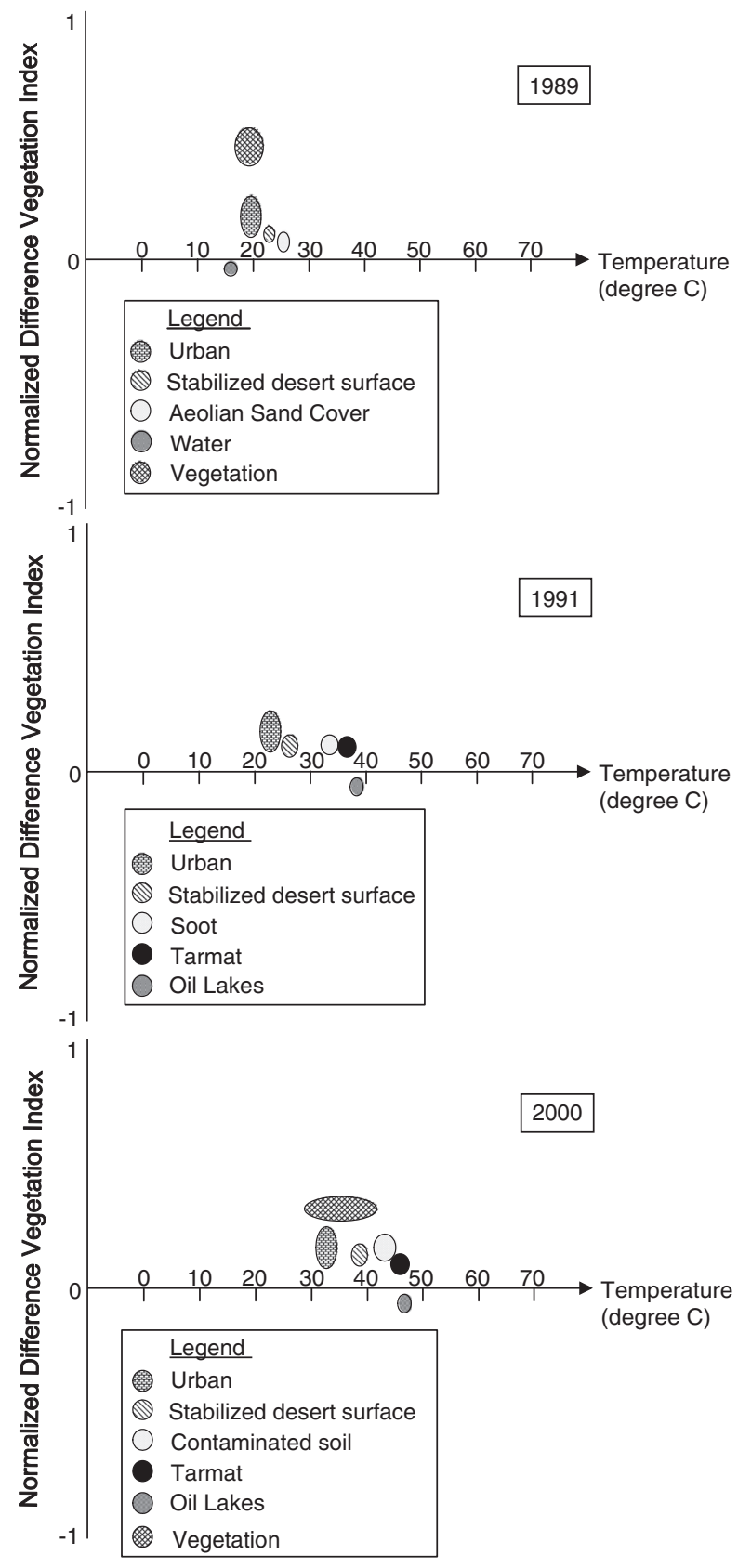

Figure 5: NDVI and temperature relationship between different land-uses.

\section{ACKNOWLEDGEMENTS}

Authors are thankful to Kuwait Institute for Scientific Research and Kuwait Environmental Public Authority for supporting the project EM037C. Thanks are due to the reviewers for their suggestions which helped us to improve the manuscript. 


\section{REFERENCES}

[1] Carlson, T.N., Dodd, J.K., Benjamin, S.G. \& Copper, J.N., Remote estimation of surface energy balance, moisture availability and thermal inertia. Journal Applied Meteorology, 20, pp. 300-306, 1981. doi:10.1175/1520-0450(1981)020<0067:SEOTSE >2.0.CO;2

[2] Balling, R.C. \& Brazell, S.W., High resolution surface temperature patterns in a complex urban terrain. Photogrammetric Engineering and Remote Sensing, 54, pp. 1289-1293, 1988.

[3] Dousset, B., AVHRR-derived cloudiness and surface temperature patterns over the Los Angeles area and their relationships to land use. Digest - International Geoscience and Remote Sensing Symposium (IGARSS), 4, pp. 2132-2137, 1989.

[4] Dousset, B., Surface temperature statistics over Los Angeles: the influence of land use. DigestInternational Geoscience and Remote Sensing Symposium (IGARSS), 2, pp. 367-371, 1991.

[5] Roth, M., Oke, T.R. \& Emery, W.J., Satellite-derived urban heat islands from three coastal cities and the utilization of such data in urban climatology. International Journal of Remote Sensing, 10(11), pp. 1699-1720, 1989. doi:10.1080/01431168908904002

[6] Quattrochi, D.A. \& Ridd, M.K., Measurement and analysis of thermal energy responses from discrete urban surfaces using remote sensing data. International Journal of Remote Sensing, 15(10), pp. 1991-2022, 1994. doi:10.1080/01431169408954224

[7] Owen, T.W., Carlson, T.N. \& Gillies, R.R., An assessment of satellite remotely-sensed land cover parameters in quantitatively describing the climatic effect of urbanization. International Journal of Remote Sensing, 19(9), pp. 1663-1681, 1998. doi:10.1080/014311698215171

[8] Voogt, J.A. \& Oke, T.R., Effects of urban surface geometry on remotely-sensed surface temperature. International Journal of Remote Sensing, 19(5), pp. 895-920, 1998. doi:10.1080/014311698215784

[9] Voogt, J.A. \& Oke, T.R., Thermal remote sensing of urban areas. Remote Sensing of Environment (Special Issue on Urban Areas), 86, pp. 370-384, 2003.

[10] Carlson, T.N. \& Arthur, S.T., The impact of land use-land cover changes due to urbanization on surface microclimate and hydrology: a satellite perspective. Global and Planetary Change, 25, pp. 49-65, 2000. doi:10.1016/S0921-8181(00)00021-7

[11] Jung, M., Henkel, K., Herold, M. \& Churkina, G., Exploiting synergies of global land cover products for carbon cycle modeling. Remote Sensing of Environment, 101, pp. 534-553, 2006. doi:10.1016/j.rse.2006.01.020

[12] Vicente-Serrano, S.M., Cuadrat-Prats, J.M. \& Romo, A., Aridity influence on vegetation patterns in the middle Ebro Valley (Spain): evaluation by means of AVHRR images and climate interpolation techniques. Journal of Arid Environments, 66, pp. 353-375, 2006. doi:10.1016/j.jaridenv.2005.10.021

[13] Nieuwolt, S., The urban microclimate of Singapore. The Journal of Tropical Geography, 22, pp. 30-37, 1966.

[14] Streutker, D.R., A remote sensing study of the urban heat island of Houston, Texas. International Journal of Remote Sensing, 23(13), pp. 2595-2608, 2002. doi:10.1080/01431160110115023

[15] Gallo, K.P. \& Owen, T.W., Assessment of urban heat island: a multi-sensor perspective for the Dallas-Ft. Worth, USA region. Geocarto International, 13, pp. 35-41, 1998. doi:10.1080/10106049809354662

[16] Gallo, K.P. \& Owen, T.W., Satellite-based adjustments for the urban heat island temperature bias. Journal of Applied Meteorology, 38, pp. 806-813, 1998. doi:10.1175/1520-0450(1999)038<0806:SBAFTU>2.0.CO;2

[17] Streutker, D.R., Satellite-measured growth of the urban heat island of Houston, Texas. Remote Sensing of Environment, 85, pp. 282-289, 2003. doi:10.1016/S0034-4257(03)00007-5 
[18] ud Din, S., Al Dousari, A. \& Literathy, P., Evidence of hydrocarbon contamination from the Burgan oil field, Kuwait - interpretations from thermal remote sensing data. Journal of Environmental Management, 86(4), pp. 605-615, 2008. doi:10.1016/j.jenvman.2006.12.028

[19] Chen, Y., Wang, J. \& Li, X., A study on urban thermal field in summer based on satellite remote sensing. Remote Sensing for Land and Resources, 4, pp. 55-59, 2002.

[20] Weng, Q., A remote sensing-GIS evaluation of urban expansion and its impact on surface temperature in Zhujiang Delta, China. International Journal of Remote Sensing, 22(10), pp. 1999-2014, 2001.

[21] Chen, Z.M., Babiker, I.S., Chen, Z.X., Komaki, K., Mohamed. M.A.A. \& Kato, K., Estimation of interannual variation in productivity of global vegetation using NDVI data. International Journal of Remote Sensing, 25(16), pp. 3139-3150, 2004. doi:10.1080/0143116032000160435

[22] Wang, J., Rich, P.M., Price, K.P. \& Kettle, W.D., Relations between NDVI and tree productivity in the central Great Plains. International Journal of Remote Sensing, 25(16), pp. 3127-3138, 2004. doi:10.1080/0143116032000160499

[23] Chen, X.L., Zhao, H.M., Li, P.X. \& Yin, Z.Y., Remote sensing image-based analysis of the relationship between urban heat island and land use/cover changes. Remote Sensing of Environment, 104, pp. 133-146, 2006. doi:10.1016/j.rse.2005.11.016

[24] Rouse, J.W.J., Haas, R.H., Schell, R.A. \& Deering, D.W., Monitoring vegetation systems in the Great Plains with ERTS. Third ERTS Symposium, NASA SP-351, Washington, DC, December 10-14, 1973, pp. 309-317, 1974.

[25] Gao, B.C., NDWI - a normalized difference water index for remote sensing of vegetation liquid water from space. Remote Sensing of Environment, 58, pp. 257-266, 1996. doi:10.1016/ S0034-4257(96)00067-3

[26] Purevdorj, T.S., Tateishi, R., Ishiyama, T. \& Honda, Y., Relationships between percent vegetation cover and vegetation indices. International Journal of Remote Sensing, 19(18), pp. 3519-3535, 1998. doi:10.1080/014311698213795

[27] Zarco-Tejada, P.J., Rueda, C.A. \& Ustin, S.L., Water content estimation in vegetation with MODIS reflectance data and model inversion methods. Remote Sensing of Environment, 85, pp. 109-124, 2003. doi:10.1016/S0034-4257(02)00197-9

[28] Jackson, T.J., Chen, D., Cosh, M., Li, F., Anderson, M. \& Walthall, C., Vegetation water content mapping using Landsat data derived normalized difference water index for corn and soybeans. Remote Sensing of Environment, 92, pp. 475-482, 2004. doi:10.1016/j.rse.2003.10.021

[29] Maki, M., Ishiahra, M. \& Tamura, M., Estimation of leaf water status to monitor the risk of forest fires by using remotely sensed data. Remote Sensing of Environment, 90, pp. 441-450, 2004. doi:10.1016/j.rse.2004.02.002

[30] Zha, Y., Gao, J. \& Ni, S., Use of normalized difference built-up index in automatically mapping urban areas from TM imagery. International Journal of Remote Sensing, 24(3), pp. 583-594, 2003. doi:10.1080/01431160304987

[31] Zhao, H.M. \& Chen, X.L., Use of normalized difference bareness index in quickly mapping bare areas from TM/ETM+. Geoscience and Remote Sensing Symposium, 3(25-29), pp. 1666-1668, 2005.

[32] Qin, Z., Karnieli, A. \& Berliner, P., A mono-window algorithm for retrieving land surface temperature from Landsat TM data and its application to the Israel-Egypt border region. International Journal of Remote Sensing, 22(18), pp. 3719-3746, 2001. doi:10.1080/01431160010006971

[33] Al Fahed, S., Al Hawaj, O. \& Chakroun, W., Recent air temperature rise in Kuwait. Renewable Energy, 12(1), pp. 83-90, 1997. doi:10.1016/S0960-1481(97)00015-3 